9 Directory of hospice services: Sydenham: St Christopher's Hospice Information Service, 1992

10 Wilkes E. Terminal care: report of a working party of the Standing Medical Advisory Committee. London: HMSO, 1980. .

11 Spitzer WO, Dobson AI Hall J, Chamberlain E, Levi J, Shepherd $\mathrm{R}$ et al. Measuring the quality of life of cancer patients: a concise QL-index for use Measuring the quality of life of cancer patient

12 Morris JN, Sherwood S. Quality of life of cancer patients at different stages in their disease trajectory. I Chronic Dis 1987;40:545-53.

13 Zigmond AS, Snaith RP. The hospital anxiety and depression scale. Acta Psychiatr Scand 1983;67:361-70.

14 Smilkstein G, Ashworth C, Montano D. Validity and reliability of the Family APGAR as a test of family function. $\mathcal{F}$ Fam Prac 1982;15:303-1 1

15 Snaith RP, Bridge GWK, Hamilton M. The Leeds scale for the self-assessment of anxiety and depression. Br f Psychiatry 1976;128:156-65.
16 Armitage P, Berry G. Statistical methods in medical research. Oxford: Blackwell Scientific, 1987

Altman D. Practical statistics for medical research. London: Chapman and Hall, 1991.

18 Addington-Hall JM, MacDonald LD, Anderson HR, Freeling P. Dying from cancer: the views of bereaved family and friends about the experiences of cerminally ill patients. Palliative Medicine 1991:5:207-14.

9 Shepherd G. Case management. Health Trends 1990;22:59-61.

20 Hurley RE. Towards a behaviourial model of the physician as case manager. Soc Sci Med 1986;23:82.

1 Rapp CA, Chamberlain R. Case management services for the chronically mentally ill. Social Work 1985;3:417-22.

(Accepted 3 September 1992)

\title{
National survey of current arrangements for diversion from custody in England and Wales
}

\author{
S Blumenthal, S Wessely
}

\begin{abstract}
Objectives-To assess the extent and nature of psychiatric assessment schemes based at magistrates' courts in England and Wales for the early diversion of mentally disordered offenders from custody and to determine the response of the NHS to new initiatives concerning alternatives to custody for this group.
\end{abstract}

Design-Postal survey of the probation service, petty sessional divisions, mental health provider units, and district purchasing authorities in England and Wales.

Subjects-All chief probation officers $(n=55)$, clerks to the justices $(n=284)$, managers of mental health provider units $(n=190)$, and purchasers of mental health services $(n=190)$ in each of the district health authorities.

Main outcome measures-Number of psychiatric assessment schemes, practical difficulties in their operation, extent of regular liaison with health and social services; current and future intentions to purchase or provide services for diversion from custody.

Results-Data were obtained from every magistrates' court. Forty eight psychiatric assessment schemes were identified with another 34 under development. Particular problems were lack of adequate transport arrangements, difficulties with hospital admissions, and overdependence on key people. There was little liaison between health, social services, and members of the criminal justice system. Twenty five of the 106 purchasers who responded had a policy dealing with diversion, and 39 had a scheme under development; 56 purchasers had no current or future plans about diversion. Sixty nine of the 150 providers who responded reported that diversion was included in their current or next business plan.

Conclusion-Schemes to divert mentally disordered offenders from the criminal justice system are often hampered by lack of adequate transport arrangements, difficulties in hospital admissions, and overdependence on key people.

Psychological Medicine

King's College Hospital

School of Medicine and

Institute of Psychiatry,

London SE5 9RS

S Blumenthal, research

worker

$\mathrm{S}$ Wessely, senior lecturer

Correspondence to:

Dr Wessely.

BMF 1992;305:1322-5

\section{Introduction}

Increasing attention is being paid to the problems of mentally abnormal offenders and the need to provide appropriate alternatives to custody, or "diversion." There is general dissatisfaction with the current system in which mentally ill people are often remanded in custody for medical reports despite widespread recognition of the inappropriateness of these arrangements.
At present once a mentally disordered offender is remanded in custody there are typically delays between requesting an assessment, receiving assessment, and hospital admission. ${ }^{2}$ Current arrangements for mentally abnormal offenders were recognised as unsatisfactory in a recent Home Office circular (66/90) which stated that "a mentally disordered person should never be remanded to prison simply to receive medical treatment or assessment" and concluded that "it is government policy that, wherever possible, mentally disordered persons should receive care and treatment from the health and social services." ${ }_{3}$ The Reed committee has recently begun to consider methods of developing and improving psychiatric services for mentally disordered offenders. ${ }^{4}$ One aspect of our review is an appraisal of present arrangements for the early diversion of mentally disordered offenders from the criminal justice system.

The Reed committee identifies a joint responsibility of the Home Office and the Departments of Health and Social Services to ensure the early diversion and improved management of mentally disordered offenders. ${ }^{34}$ The aim of diversion is to reduce the role of the criminal justice system and increase that of the health service. In response liaison schemes providing a psychiatric assessment service at magistrates' courts have appeared in various parts of the country. These schemes have not been surveyed systematically and there is no information about local variations in the coverage of, and need for, such facilities. There is also no information on how regional and district health authorities have responded to the Home Office's circular $66 / 90$ and the recommendations of the Reed committee. It is unclear how the new NHS structures have affected services for mentally disordered offenders and what roles purchasers and providers perceive themselves to fulfil.

We report a comprehensive survey of the extent of diversion schemes in England and Wales and the way in which new health service structures have responded to current directives to improve psychiatric services to mentally disordered offenders.

\section{Methods} officers in each of the probation areas $(n=55)$, the clerks to the justices responsible for each of the petty sessional divisions $(n=284)$, and the purchasers $(n=190)$ and providers $(n=190)$ with responsibility for mental health services in each of the district health authorities in England and Wales.

The questionnaire to the probation officers and
A postal survey was undertaken of chief probation 
clerks to the justices requested factual information on diversion schemes in their area as well as the attitudes and perceptions of other agencies involved. At present, most court liaison schemes are run by forensic psychiatrists. All psychiatrists with a full time forensic post were surveyed $(n=70)$, and similar information was obtained.

The questionnaires to the purchasers requested information on current and future purchasing intentions, the extent to which purchasers were aware of issues related to services for mentally ill offenders, and the level of priority afforded to the provision of these services.

The managers of mental health provider units were sent a questionnaire covering general policy issues, including details of current or future strategic, operational, and business plans for services to mentally disordered offenders. Information was also sought on formal contact between the health service and the criminal justice system, and reasons for absence of such contact if appropriate.

We defined a diversion scheme as an arrangement between a magistrates' court and a psychiatrist whereby the psychiatrist attends the court regularly (or is on call and can be available rapidly) to assess defendants who are suspected of being mentally disordered and to advise the court on alternatives to custody if appropriate. This definition includes the use of a panel scheme whereby a community psychiatric nurse or approved social worker attends the court regularly and brings mentally abnormal defendants to the attention of other mental health professionals working in a multiagency team that jointly arranges diversion and management.

\section{Results}

We received completed replies from 53 (96\%) chief probation officers, $162(57 \%)$ clerks to the justices, 60 $(86 \%)$ forensic psychiatrists, and $106(56 \%)$ purchasers and $150(79 \%)$ providers of mental health services.

We assumed that non-responders among purchasers were likely to have less interest in or fewer plans concerning mentally abnormal offenders. However, a random sample of 17 non-responders $(20 \%$ of all non-responders) was followed up by telephone and indicated a similar pattern of answers to responders. The principal reason given for non-response was the lack of clearly defined areas of responsibility for diversion. Many of the purchasers passed the questionnaire on to the provider unit in their district who had usually already completed a questionnaire.

TABLE I-Numbers of diversion schemes planned and operational in England and Wales

\begin{tabular}{|c|c|c|}
\hline $\begin{array}{l}\text { Regional } \\
\text { health } \\
\text { authority }\end{array}$ & Operational & Planned \\
\hline East Anglia & 5 & 1 \\
\hline Mersey & 0 & 1 \\
\hline Northern & 3 & 4 \\
\hline \multicolumn{3}{|l|}{ North East } \\
\hline \multicolumn{3}{|l|}{ North West } \\
\hline Thames & 7 & 4 \\
\hline \multicolumn{3}{|l|}{ North } \\
\hline Western & 4 & 1 \\
\hline $\begin{array}{l}\text { Oxford } \\
\text { South East }\end{array}$ & 6 & 2 \\
\hline $\begin{array}{c}\text { South East } \\
\text { Thames }\end{array}$ & 5 & 3 \\
\hline \multicolumn{3}{|l|}{ South West } \\
\hline Thames & 2 & 2 \\
\hline \multicolumn{3}{|l|}{ South } \\
\hline Western & 1 & 1 \\
\hline Trent & 3 & 1 \\
\hline Wessex & 4 & 1 \\
\hline \multicolumn{3}{|l|}{ West } \\
\hline Midlands & 3 & 2 \\
\hline Yorkshire & 2 & 3 \\
\hline Wales & 0 & 2 \\
\hline
\end{tabular}

Data were obtained from every magistrates' court in England and Wales. A total of 48 psychiatric assessment schemes were identified with a further 31 under development (table I). An appendix of these schemes is available from us.

\section{PRACTICAL PROBLEMS}

Only $12(25 \%)$ chief probation officers whose areas had diversion schemes indicated that they had formal transport arrangements to take mentally ill offenders to hospital once diverted from custody. In areas without transport arrangements this was seen as a major obstacle to the success of the scheme. In areas with diversion schemes the probation service also reported difficulties with hospital orders, informal admissions, and outpatient treatment (see table II). The probation service reported that arrangements for compulsory admissions, informal admissions, and outpatient treatment were unsatisfactory in half of those areas that had schemes, and substantially more so in areas with fewer resources.
TABLE II-Composition of and practical difficulties encountered with court diversion schemes

\begin{tabular}{lc}
\hline & $\begin{array}{c}\text { No of } \\
\text { schemes } \\
(\mathrm{n}=48)\end{array}$ \\
\hline Regular attendance of court by a psychiatrist & 14 \\
Regular attendance by a community psychiatric nurse & 10 \\
Regular attendance by an approved social worker & 7 \\
Dependent on key person & 41 \\
At risk of closure should key person leave & 22 \\
Adequate transport arrangements & 12 \\
Shortage of beds and mental health staff & 10 \\
Unsatisfactory arrangements for outpatient treatment & 26 \\
Unsatisfactory arrangements for informal admissions & 24 \\
Unsatisfactory arrangements for hospital orders & 24 \\
\end{tabular}

A further problem concerned many of the schemes' overdependence on the efforts of a key person. This was evident in $46(85 \%)$ areas with liaison schemes. The probation service indicated that just over half of them $(53 \%)$ would not continue if the key person left. This was corroborated by similar reports from the clerks to the justices.

Both the probation officers and the clerks to the justices were encouraged to make further unstructured comments. Many reported difficulties in the admission of patients under the provisions of the Mental Health Act 1983. Many hospitals were reluctant to accept admissions of mentally abnormal offenders because of the threat of violence to hospital staff. Problems were encountered with most operational schemes, mostly concerning interagency communication and cooperation. In instances when an offender was admitted to hospital under a part 3 (criminal) order of the act the hospital often delayed admitting the patient unless a part 2 (civil) order had been made. The problem is occasionally overcome only by the psychiatrist seeking a discontinuance from the Crown Prosecution Service. ${ }^{125}$

\section{SATISFACIION}

As expected, probation officers in areas with diversion schemes in operation were more likely to regard their arrangements as effective $\left(\chi^{2}=25 \cdot 84, \quad \mathrm{df}=3\right.$; $\mathrm{p}=0.0001)$. This was also true of providers of mental health services $\left(\chi^{2}=8 \cdot 36, d f=3 ; p=0 \cdot 03\right)$. Surprisingly, the degree of cooperation and support from local psychiatrists when a probation order with psychiatric conditions had been made did not differ between areas with schemes in operation and those without $\left(\chi^{2}=1 \cdot 16\right.$, $\mathrm{df}=1 ; \mathrm{p}=0 \cdot 28$ ).

The lack of diversion schemes in areas without such arrangements does not reflect lack of need. In four of the five probation areas without schemes a minimum of between one and five offenders were dealt with for whom diversion would be considered appropriate, and only one had fewer than one offender a month.
LIAISON BETWEEN HEALTH SERVICE AND CRIMINAL JUSTICE SYSTEM

The probation service had regular contact with the health service (described as meeting with a consultant psychiatrist regularly) in 25 of the 53 probation areas which replied $(47 \%)$. In 17 areas these were regular meetings with social services.

The health service reported that most regular liaison with the criminal justice system was with the police service $(72(48 \%)$ provider units), the probation service $(63(42 \%))$, and the prison service $(48(32 \%))$. Regular attendance at court $(20(13 \%)$ provider units) and regular liaison with the Crown Prosecution Service (24 $(16 \%)$ ) was unusual. However, providers were most likely to be considering regular attendance at court $(50(33 \%))$.

Among health authorities that had schemes for diversion from the criminal justice system few had 
included regular attendance at a police station, court, or prison as part of any mental health professionals' job plan, and it was not under consideration. Regular meetings between members of the health service and other agencies participating in diversion were also sparsely reported.

HEALTH SERVICE POLICY DEALING WITH SERVICES FOR MENTALLY ABNORMAL OFFENDERS

Of purchasers who responded, $89(84 \%)$ indicated an awareness of the Home Office's circular 66/90. However, only $22(25 \%)$ indicated that they had a policy dealing specifically with mentally disordered offenders. Of the remaining $67,33(31 \%)$ reported that a policy was likely to be developed in the following 12 months. Thus $34 \%$ of all purchasers had no current or future plans to develop a policy; $53 \%$ (56) of purchasers did not regard the setting up of schemes for diversion as a priority.

IMPLEMENTATION OF HEALTH SERVICE POLICY FOR MENTALLY ABNORMAL OFFENDERS

There was consistency between purchasers having a policy dealing with mentally disordered offenders and the implementation of policy in the form of a purchasing plan $\left(\chi^{2}=4.9, \mathrm{df}=1 ; \mathrm{p}=0.02\right)$. Twenty seven $(25 \%)$ purchasers reported a policy dealing specifically with mentally disordered offenders, and $21(20 \%)$ stated that they had included a service in their purchasing plans.

With regard to future purchasing intentions, 33 of the 53 respondents who had not included diversion in their present purchasing plans indicated that they expected to include it in the next 12 months. It is, of course, impossible to say how well those intentions will be translated into action. What can be said is that $50 \%$ of purchasers do not have any plans to implement Home Office circular 66/90.

Mental health provider units reported few business plans dealing with diversion from the criminal justice system at police stations $(19(15 \%)$ units $)$, courts $(19(15 \%))$, and prisons $(16(11 \%))$.

More encouraging was the extent of future plans for providing services to mentally ill offenders among mental health provider units. Eighteen of the 53 purchasers who had not made current provision stated that they would be doing so in their next business plan.

\section{REGIONAL VARIATIONS}

Table III shows the number of mental health provider units within each region with provision for diversion from custody in their current or future business plan.

TABLE III-Regional variations in numbers of provider units with diversion of mentally disordered offenders from custody included in present or future business plan. Values are numbers of district health authorities

\begin{tabular}{lcccc}
\hline & $\begin{array}{c}\text { No of districts that have or } \\
\text { will include diversion in } \\
\text { their present or future } \\
\text { business plan }\end{array}$ & & \\
\cline { 2 - 4 } Regional health authority & $\begin{array}{c}\text { Diversion } \\
\text { included }\end{array}$ & $\begin{array}{c}\text { Diversion } \\
\text { not included No response }\end{array}$ & Total \\
\hline East Anglia & 3 & 2 & 3 & 8 \\
Mersey & 3 & 5 & 2 & 10 \\
Northern & 3 & 4 & 9 & 16 \\
North East Thames & 5 & 7 & 3 & 15 \\
North West Thames & 6 & 6 & 1 & 13 \\
North Western & 8 & 7 & 4 & 19 \\
Oxford & 4 & 4 & 0 & 8 \\
South East Thames & 7 & 4 & 4 & 15 \\
South West Thames & 2 & 6 & 5 & 13 \\
South Western & 5 & 4 & 2 & 11 \\
Trent & 7 & 4 & 1 & 12 \\
Wessex & 2 & 6 & 2 & 10 \\
West Midlands & 4 & 11 & 6 & 21 \\
Yorkshire & 8 & 4 & 4 & 16 \\
Wales & 4 & 4 & 1 & 9 \\
\hline
\end{tabular}

REASON GIVEN FOR ABSENCE OF ARRANGEMENTS

There was disagreement between clerks to the justices and chief probation officers on the reasons for the absence of diversion schemes in areas without arrangements. The clerks to the justices were more likely to cite the lack of appropriate cases for diversion $(123(76 \%))$. On the other hand, the probation officers were more likely to list the lack of adequate resources $(34(64 \%))$ and the lack of sufficient beds to accommodate mentally disordered offenders $(29(55 \%))$. Also mentioned was the lack of cooperation of psychiatrists $(19(36 \%))$, the lack of interest of mental health staff $(14(27 \%))$, too few cases for which diversion was considered appropriate $(21(39 \%))$, and the need for the probation service to develop a more positive approach $(24(45 \%))$.

The reasons most frequently cited by the health service were the lack of adequate resources $(66(44 \%))$, insufficient beds to accommodate mentally disordered offenders $(57(38 \%))$, and the perception that there were too few cases for which diversion is deemed appropriate $(57(38 \%))$.

\section{Discussion}

The overall picture of the extent of court based psychiatric assessment schemes was constructed from information supplied by people working within the criminal justice system and the health service who have responsibility for mentally disordered offenders. The survey raised questions on the variation of local requirements for diversion schemes, the need for interagency collaboration, and identified common problems encountered by those operating psychiatric assessment schemes.

Various different models of psychiatric assessment schemes for diversion were encountered across England and Wales. Some are operated on the initiative of an individual psychiatrist who attends court as part of a research session. In others arrangements for diversion can be organised as part of local regional or district services, and the various participating agencies contribute on the basis of expected contractual procedure. The multiagency panel scheme has been adapted in various parts of the country according to the local demand for a service.

Because of large variations in local need, regular attendance by psychiatrists is not always indicated. In many of the rural areas current arrangements, with an on call psychiatrist, were seen as satisfactory (although this does not necessarily mean that arrangements are effective). The geographical diversity of needs and local circumstances mean that no single scheme or policy would be appropriate nationwide, but the current arrangements remain inadequate in many areas, and of those areas without schemes, most probation services continue to report large numbers of offenders who are considered appropriate candidates for diversion.

Regional variations in the provision of services for diversion from custody may not simply reflect differences in the need for such services. Our impression is that the existence of psychiatric assessment schemes is often associated more with the availability of local forensic services (and interested staff) than local need. The different responses of the clerks to the justices and the chief probation officers to questions on need illustrates the difficulty in making an assessment of local requirements.

The interagency nature of the diversion of mentally disordered offenders requires that there be appropriate networks for communication between the different groups. Regular contact between the health service, the criminal justice system, and social services is one indication of the state of cooperation among the 
different agencies and was found in only a minority of areas. Mental health provider units reported even less contact. The lack of interagency liaison was usually not a consequence of few offenders requiring diversion.

Many commented that interagency cooperation is not straightforward to arrange, even when the agencies are willing. Each service is divided on a different geographical basis and boundaries are not coterminous. Both probation areas, which are divided roughly by county, and magistrates' courts, which are organised on the basis of petty sessional divisions, cut across health authority boundaries.

The responses, both structured and unstructured, from the criminal justice system identified several practical difficulties. These usually concerned liaison with local psychiatric services, particularly the common reluctance to accept admissions (especially if compulsory) and difficulty in arranging transport to hospital. Many noted that cooperation with hospitals is impeded by the fear of violence, reluctance to accept unpopular patients, and, increasingly, a shortage of hospital based resources. All of these were compounded by the lack of interagency cooperation.

The difficulty concerning arrangements to transport mentally disordered offenders to hospital highlights the issue of who takes responsibility for the patient or offender. In many cases ambulance staff refuse to take the defendant to hospital because of their security risk, the police refusing because transport to hospital is the responsibility of the health service. One psychiatrist arranged taxis to convey mentally disordered offenders to hospital. Court liaison schemes frequently commented that duty psychiatrists spend a great deal of time finding a hospital bed and arranging transport. Comparatively little time was spent in assessments.

The survey also raised doubts about the future of many schemes. We report that the assessment arrangements currently in operation are often the result of the efforts of a key person. The continuation of many of these schemes is dependent on the response of purchasers and providers of mental health services in the NHS. The provision of services to mentally disordered offenders is intended to follow negotiation between the commissioning agents and the providers of mental health services in health districts. However, the results of the survey of commissioners suggests that their general level of awareness of their role as purchasers of mental health services for offenders is not satisfactory.

As well as the figures themselves, we encountered other indications that not all purchasers are equally aware of their role in the planning and provision of services for mentally abnormal offenders. Twenty one per cent of the questionnaires were passed on to the provider units to be completed. In one case the researcher was telephoned by a purchaser who stated clearly that diversion was of no relevance to his authority and refused to complete the questionnaire. The response rate among this group was well below average, even though non-respondents were posted reminders and some were telephoned.

Most provision by the health service of diversion from the criminal justice system is still arranged informally. Having a policy dealing specifically with mentally disordered offenders and implementing it remain the exception rather than the rule. However, among both purchasers and providers of mental health services there were indications that improving arrangements for diversion is a service priority, but that these plans are perceived as dependent on the increased provision of resources. Even when a need for diversion schemes was recognised, regular and formal contact with the criminal justice system was often seen as impractical because of resource implications.

Mentally disordered offenders require facilities for treatment and care once they have been diverted from custody. The problem of the "revolving door," where follow up treatment and care facilities are insufficient and mentally ill individuals shift between penal system, hospital, and the streets, is well known. ${ }^{\circ}$ Many of the schemes currently operating have adequate provisions for psychiatric assessment but inadequate arrangements for follow up treatment and care of the offender once diverted from custody. Of particular note are the inner city schemes in London, where the shortage of beds is a major problem. ${ }^{7}$ A further gap is the provision of medium secure beds presently provided by regional secure units. ${ }^{8}$

Diversion schemes mean increases in admissions and greater demand on already limited resources. Resistance to the setting up of psychiatric assessment schemes reflects concern not only for the cost of the scheme itself but also for the costs of treating and housing mentally ill offenders.

\section{Conclusions}

Providers have considerable awareness of the need to develop services for mentally disordered offenders, although these are more often in the planning than the implementation stage. There are, however, more gaps in purchaser awareness of their role regarding services for abnormal offenders.

When diversion is necessary, the commonest obstacle cited by the NHS is lack of resources. However, as the probation service frequently cites lack of interest by the mental health services as a barrier to further developments, it remains to be seen whether lack of resources or interest is the real obstacle to the future development of services.

Although there are gaps in liaison between the health service and the criminal justice system, the current focus on services for mentally abnormal offenders has created considerable interest and good will, and even during the course of the survey we noted positive changes in attitude. What remains to be seen is how interest is translated into activity. Currently the response remains fragmented and occasionally fragile.

We thank Mr Geoff Dobson, Mrs Dorothy Tonak, Mrs Pamela Charlwood, Dr Philip Joseph, Dr John Wilkins, Dr Glyn Lewis, and Dr Adrian Grounds for their help. We thank Dr Derek Cooper and Ms Patsy Dixon for their help in data management. We thank the Association of Chief Officers of Probation and Justices' Clerks Society for their cooperation. This study was funded by the Department of Health. The views expressed are our own.

1 Joseph P. Psychiatric assessment at the magistrates' court. London: Home Office and Department of Health, 1992

2 James D, Hamilton $\mathrm{L}$. The Clerkenwell scheme: assessing efficacy and cost of a psychiatric liaison service to a magistrates' court. $B M F$ 1991;303:282-5.

3 Home Office. Provision for mentally disordered offenders. London: Home Office, 1990. Circular 66/90.

4 Department of Health and Home Office. Reports of the service advisory groups: an overview. Review of health and social services for mentally disordered offenders and others requiring a similar service. London: Department of Health, 1991. (Reed committee.)

5 James D, Hamilton L. Setting up psychiatric liaison schemes to magistrates' courts: problems and practicalities. Med Sci Law 1992;32:167-76.

6 Jones H. Revolving doors. London: NACRO Publications, 1992

7 Hirsch SR, Craig T, Dean C, Hollander D, Holloway F, Howat J, et al. Facilities and services for the mentally ill with persisting severe disabilities. Working party report on behalf of the Executive Committee of the General Psychiatry Section of the Royal College of Psychiatrists. London: Royal College
Pstalter Psychatry Section of the
of Psychiatrists, 1992.

8 Fennell P. Diversion of mentally disordered offenders from custody. Criminal Law Review 1991 May:333-48.

(Accepted 6 October 1992) 